\title{
Experience of teaching mathematics at the technical trainers college (TTC) in Saudi Arabia
}

\author{
Gerard O’Regan \\ ICT Department, Technical Trainers College, Riyadh, Saudi Arabia \\ For correspondence: gerard.o'regan@giz.de
}

\begin{abstract}
The Kingdom of Saudi Arabia (KSA) has embarked on a major education initiative, and is currently setting up several Colleges of Excellence ( $\mathrm{CoE}$ ) to provide world class vocational training in the country. These colleges will be run by international education providers, and the objective is to raise the bar in technical education across the country, and to provide graduates every opportunity to obtain high quality jobs and to build a successful future. The Technical Trainers College is an important part of the $\mathrm{CoE}$, and it plays an essential role in preparing young Saudis to become teachers at third level vocational colleges in the Kingdom. It is run by the German Agency for International Cooperation (Deutsche Gesellschaft für Internationale Zusammenarbeit (GIZ) GmbH). GIZ is active in development projects around the world, and it has been involved in projects in Saudi Arabia since the 1960s. It is currently managing a technical college in Yanbu as well as the TTC in Riyadh. This paper discusses the challenges of teaching mathematics at the TTC in Saudi Arabia, and the problems that need to be overcome to enable students to attain a reasonable level of competence in the discipline.
\end{abstract}

Keywords: Colleges of Excellence, TTC, TVTC, CoE, CoT, CEFR, IELTS, NOSS, SSS

\section{Introduction}

The Kingdom of Saudi Arabia is making major investments in education, and is currently setting up several Colleges of Excellence to provide world class vocational training (Al-Khotani, 2014). The colleges will be run by international education providers, and the objective is to raise the bar in technical education across the country, and to enhance the employability of graduates from the colleges. The Colleges of Excellence will ensure that their training courses are designed and delivered to meet the needs of employers, and this will ensure that graduates of the colleges possess the appropriate knowledge and skills to find appropriate employment and to be successful in their careers.

Initially ten colleges will operate from September 2014, and these will be run by international education providers such as Algonquin, TQ, Nescot, Mondragon and Laureate. Initially, the teaching staff will be international experts, but targets have been set for Saudis to replace international staff over time. The process of replacing expatriate workers with Saudi workers is termed Saudization, and the Kingdom has embarked on a major Saudization initiative with the goal of providing more employment for its citizens.

It is therefore essential to develop a highly skilled workforce to enable Saud citizens to participate actively in the workplace, and to reduce its dependence on expatriate workers. Currently, about $10 \%$ of Saudi workers participate in Technical and Vocational training, but there are plans for a massive expansion of this number to reach about $43 \%$ over the next eight years. This will allow the KSA to catch up with other countries in the developed world. The existing (approx. 100,000) students in vocational education will be increased to about 450,000 students by 2020 (Al-Khotani, 2014) . 
There will be a strong focus on the quality of the education and training, and it will be designed and developed to meet the needs of employers. This will enhance the employability of the graduates, and allow them to build successful careers.

The National Occupation Skills Standards (NOSS) specifies the knowledge and skills required for each occupation category. The NOSS is approved by leading employers in the KSA to ensure that it meets their needs, and the Colleges of Technology are required to design and deliver training courses to meet these requirements.

GIZ has been involved in the definition of the NOSS for the various occupation categories, and best practice in Occupational Skills Standards from the United Kingdom, New Zealand and Germany have been employed (NOSS, 2014). Personnel from the Saudi Skills Standards (SSS) will conduct institutional reviews of the colleges on a periodic basis to ensure that the quality of education and training that the students receive meets the needs of the KSA (SSS, 2014).

The Technical Trainers College (TTC) is an important part of the CoE, and it plays an essential role in preparing young Saudis to become teachers at third level vocational colleges in the Kingdom. It is run by the German Agency for International Cooperation (GIZ), and GIZ is active in development projects around the world. It is currently managing a technical college in Yanbu as well as the TTC in Riyadh.

This paper discusses the challenges of teaching mathematics at the TTC in Saudi Arabia, and the problems that need to be overcome to enable students to attain a reasonable level of competence in the discipline.

The Saudi primary and secondary level system is dominated by tedious rote learning and religious instruction, with limited time spent on critical thinking and problem solving (Murphy, 2011). This means that students often lack the ability to think creatively about a subject, and they are often incapable of problem solving and thinking outside the box. This means that the students entering the TTC often have extremely weak foundations in mathematics, and that therefore the focus needs to be on putting solid foundations in place before any more advanced mathematics can be taught.

Students often lack confidence in mathematics and tend to be most comfortable when they have a rule that they can follow with minimal reflection and analysis. The students vary in motivation but in general respond well to class-room based activities. They tend to respond best to practical exercises rather than theory, and it is essential to keep students busy in solving exercises rather than spending a long time on theory. Teaching is further complicated by the fact that often students have limited language skills in English.

The students that attend the TTC are graduates of the existing Colleges of Technology in Saudi Arabia, and so most are in their early twenties. However, their maturity is a lot less than their western counterparts due to the specific culture of Saudi Arabia. There is strict segregation of the genders in the KSA, and contact between the genders is kept to a minimum. The Colleges of Excellence will be all male or all female.

The standards in the new Colleges of Excellence is expected to be far superior to the existing Colleges of Technology, and so the quality of the intake into the TTC is expected to substantially improve when the first graduates of the colleges of excellence apply to the TTC. The Saudi Skill Standards will monitor the quality of training provided by the colleges to ensure that it is fit for purpose and meets the needs of the KSA. 


\section{Saudi Arabia}

Saudi Arabia has gone through major transformations over the last sixty years from a traditional Arab Bedouin society with various tribes living a semi-nomadic life in the desert, to modern times where the Arab population have settled in cities such as Riyadh on the Arabian Peninsula. The Bedouin heritage of the country means that a culture of learning is relatively new for its citizens, and students often lack the discipline of reading, studying and problem solving. This means that the education of young Saudis is likely to be a long-term project, with perhaps another generation required before it reaches international standards.

Saudi Arabia is a petroleum driven economy which relies on several million expatriate workers to do most of the work in the private sector (IMF, 2013). Currently, there are very high-levels of unemployment among Saudi youth, with the official figures for 2009 indicating that $30 \%$ of Saudis aged 15 to 24 years were unemployed. It is a very young population with $37 \%$ of Saudis under the age of $14,51 \%$ under the age of 25, and $66 \%$ under the age of 40 (Murphy, 2011). The government therefore wishes to provide employment for its young citizens, and to minimise the risk of social unrest in the country. However, young Saudis often lack the qualifications and experience to participate in the workforce, and so there needs to be a major emphasis on vocational training to enable young Saudis to develop the required skills to be successful in the workplace, as well as fostering a culture of innovation and entrepreneurship in the country.

Currently, there is a very low level of female participation in the workforce, and while the education of females has significantly improved the characteristics of Saudi society make it difficult for females to participate actively in the workforce. Female unemployment was $45.8 \%$ in 2008 and there was an unemployment rate of $78 \%$ for young women with a bachelor's degree (Murphy, 2011). Saudi Arabia is the only country in the world in which females are not permitted to drive a car, and while there has been a long debate as to whether females should be permitted to drive, to date, no progress has been made. Females need permission from their guardians to travel outside the country, and they need to hire drivers or arrange with male family members to drive them to work or to college. It is therefore hardly surprising that females comprise a low percentage of the workforce.

\section{Education in Saudi Arabia}

The study of Islam is a major part of the Saudi educational system and students spend a significant part of their studies memorizing large parts of the Qur'an, and its application to Saudi society. Islam is a compulsory subject at school, technical colleges and universities, and traditionally the emphasis in the education system has been on rote learning which limits the creativity and innovation of Saudi students. It is emphasised to the students that the ruling monarchy is the protector of the Islamic faith, and this acts to legitimise its absolute rule and to maintain power and wealth in the hands of the ruling elite. However, education reforms are underway with the goal of the replacement of rote learning by modern pedagogical techniques (Al Kinai, 2013).

There are three types of Saudi school: primary school for ages from $6-12$; intermediate schools from ages 12 - 15; and secondary schools for ages from 15 - 18. All schools in Saudi Arabia (apart from the international schools) are single gender. The approximate participation rate is approximately $98 \%$ at primary level; $96 \%$ at intermediate level; and 92\% at secondary level (EdKSA, 2014).

The third level sector consists of colleges of technology and universities. There are over thirty universities in the country, and approximately $60 \%$ of Saudi university students are female and $40 \%$ male. Among the well-known Saudi institutions are the King Saud University, King Abdul-Aziz University, King Faisal University, and King Abdullah University of Science and Technology (KAUST). 
The King Abdullah scholarship program was introduced in 2005, and it allows young Saudis to pursue undergraduate or postgraduate degrees at western universities. The scholarship covers tuition fees and living expenses for up to four years, and thousands of Saudis have taken the opportunity to study abroad.

The Technical and Vocational Training Corporation (TVTC) has traditionally been responsible for vocational training in the KSA, and the importance of vocational training is recognised in the Kingdom. However, the KSA has recently set up several Colleges of Excellence independent of the TVTC to provide world class vocational training. Currently, there are approximately 100,000 students in vocational education in Saudi Arabia, and the plan is to expand this to 450,000 students by 2020 . The goal is to achieve the highest possible international standards through the use of international education providers, and to develop a highly skilled workforce to enable Saud citizens to participate actively in the workplace, and to reduce its dependence on expatriate workers.

\section{Technical Trainers College}

The TTC offers a three year internationally accredited bachelor's degree in Engineering Technology (BET) in a range of technical disciplines including information technology, electrical technology and mechanical technology. The language of instruction is English and the specific disciplines taught at the college include:

- Information and Communication Technology

- Electrical \& Electronics Technology

- Mechanical Technology

- Vocational Pedagogy

- English

- Islamic Studies

- Company Field Practice

- Continuing Education

Students acquire practical experience through six-week internships during the summer period, and practical teaching experience through applied vocational pedagogy.

The TTC embarked on a new project "Continuing Education" in 2013, and the goal is to offer organizations in Saudi Arabia courses tailored to their needs. These courses are based on European standards and are certified by the Central Accreditation and Evaluation Agency (ZEvA) based in Germany.

\section{Intake Assessment Test}

The TTC conducts an entrance examination to select the most suitable students to study at the college. The intake assessment test determines the standard of the students in Mathematics and English, and the students are ranked accordingly.

The goal of the intake assessment test has been to raise the quality of the intake. However, at this time the number of students who apply to the college and do the assessment test roughly matches the number of places available at the college. Therefore, in practice almost all students who take the assessment test are granted admission to the college at this time.

However, it is expected that the number of applicants will increase significantly in the coming years, and this will allow the college to be more selective on the students that it accepts. 
The results of the assessments tests at this time indicate that the students lack the appropriate foundation in mathematics and the appropriate English language skills. They typically achieve a low A1 on the Council of Europe Framework Scale (CEFR scale) which is roughly equivalent to the International English Language Testing Service (IELTS) score of 2 in English, and their mathematical ability is equivalent to what a western student would have in the early years of high school.

\section{Preparation Semester}

The TTC has recognised that action is needed to assist Saudi students with their weak foundations in Mathematics and English, and the college has recently introduced a preparatory semester to deal with this.

Students who pass the intake assessment examination are accepted directly into the college, while all other students who have not met the required minimum standard are required to do a preparatory semester to enhance their capability in Mathematics and English.

The preparatory semester provides intensive instruction in English and Mathematics, and students who do the preparatory semester are required to re-sit and pass the intake assessment test prior to their acceptance at the college.

\section{Teaching Mathematics at the TTC}

The standard of mathematics among the students at the TTC initially comes as a culture shock to international staff. Students often lack the ability to do the simplest of calculations without a calculator, and constantly make errors in basic arithmetic operations. International staff are initially shocked and perplexed that the students seem to know so little about mathematics, despite the fact that they are already graduates of a college of technology in Saudi Arabia.

$$
\begin{aligned}
& (x+4)(x+2)= \\
& \frac{1}{4}+\frac{1}{5}= \\
& {\left[\frac{2}{3}\right]^{-3}=} \\
& (-2)(-3)= \\
& 81^{\frac{3}{4}}= \\
& \frac{1}{x+4}-\frac{1}{x+2}
\end{aligned}
$$

Figure 1. Simple Calculations

Figure 1 presents examples to illustrate the lack of competence of the students. Many of the students have no idea how to determine the solution to these elementary problems without a calculator, and there is a serious lack of competence among the students in elementary algebra, in the addition and subtraction of fractions, in determining powers and roots and so on.

There is no silver bullet to resolve the weak foundations of the Saudi students and the approach taken at the TTC is to devote the preparatory semester to strengthen the foundations of the students. Mathematics in the preparatory semester includes an introduction to numbers; highest common factor and least common multiple; arithmetic operations with fractions; ratios and percentages; 
algebraic expressions; powers and roots; area and volume; basic trigonometry; and Cartesian coordinates.

The English language skills of the students at the TTC are initially quite limited, and their competence on entry is approximately that of an IELTS score of 2. It is therefore useful to adopt a "peer learning" approach to the teaching of mathematics, as experience suggests that better results are achieved with a bilingual explanation. In practice this means identifying the stronger students early in the semester, and encouraging them to give explanations in Arabic to the class.

It is essential to have active participation of all the students, and the approach taken is to do a little theory, and then to do lots of exercises. The goal is to have an atmosphere that is conducive to learning, and to get the students actively involved. All students come to the whiteboard to present solutions to the problems, and to explain the solution to their peers. This helps in building confidence in the students, and encourages them to try even harder. If a student has difficulty in completing or in explaining the exercise at the whiteboard support is provided from one of his colleagues or by the teacher.

Several class tests are conducted during the semester as part of continuous assessment and to identify the weakest students early. The weakest students are encouraged to apply themselves fully, to study harder, to do regular homework, and to ask questions when they do not understand. A tutor may be appointed to the class to help with revision and to assist the weaker students. Homework is given regularly during the semester to give the students extra practice.

The use of calculators is kept to a minimum until more solid foundations are in place. In general, teaching at the TTC requires a lot of patience and humour, as students will often make silly mistakes or fail to solve an elementary problem. It is important to build good human relationships to be effective in Saudi culture, and this applies as well to the teacher-student relationship.

Good relationships can be built by remembering the first names of students although it can be quite a challenge to remember names such as Abdullah, Faisal, Omar, Yasser, and so on. Students also respond well to encouragement. It also helps if the teacher works on a personal relationship with the students, and discusses their progress on a one-to-one basis during the semester. This helps in motivating students to perform better, and students benefit from encouragement and praise when they do well.

It is important to remember that a generation or so ago the majority of the Saudi people were living as Bedouin tribes in the desert, and so they have come a long way. It is important to provide support here and to realize that it will take the society here some time to reach international standards.

The students tend to be surprised by the scores that they receive in examinations. It seems that at secondary education and at the existing Colleges of Technology it is quite common for students to receive scores of $90-95 \%$. It seems that teachers in Saudi schools and the existing colleges of technology give these scores to the students irrespective of their standard. Saudi students are often unaware of the major gap in their knowledge when compared to their international peers. Another phenomenon that appears to be unique to education in the KSA is that students occasionally come to the lecturer's office after an examination to bargain (or plead) for a higher score. The thinking seems to be that if you like the student on a human level then it is appropriate to reward or to help the student with higher marks.

The existing educational system in the KSA encourages rote learning rather than deep reflection on a topic, and students tend to forget what they have learned quite quickly. Students often lack the 
discipline of regular study, and seem to lack the awareness of the value of the library as a place to go to read more about a topic. Students are encouraged to go to the library to consult other books on mathematics such as (O'Regan, 2013), although to date only limited progress has been made with this.

Following the preparatory semester students study simultaneous equations, quadratic equations, trigonometry, logarithms and exponentials, and vectors in the first semester. The ICT and EET majors study an introductory course in Calculus in the second semester, and the ICT majors also study a short course on Mathematical Logic. Currently, this is the extent of mathematics currently taught at the TTC, but the curriculum is currently under revision, and it is intended to teach a more advanced calculus course, discrete mathematics and logic, and probability and statistics to the ICT majors in the future.

\section{Future Plans for Mathematics Education at the TTC}

The TTC is committed to continuous improvement, and is currently revising its education curriculum to ensure that it will meet the future education needs of its students. This will see the provision of additional courses in mathematics for the ICT majors such as Probability and Statistics; an additional Calculus course to cover more advanced topics; and Discrete Mathematics and Logic.

The college has evaluated several tools to support learning in mathematics. This included an evaluation of the TInspire tool from Texas Instruments. It was noted that this tool had some nice class room management capabilities, but that it has limited use for students at the TTC at this time, given that the focus is on improving the foundations. At this time such a tool would be a distraction to students.

However, the Vocational Pedagogy department in the TTC has expressed an interest in this tool to demonstrate to the students how tools may be employed to teach mathematics. In fact, a number of schools in the KSA (e.g., the American International School in Riyadh) use the TInspire technology.

\section{Summary and Conclusions}

The Kingdom of Saudi Arabia is making major efforts to improve the quality of vocational education in the country, and to enhance the employability of its citizens. It has set up several Colleges of Excellence which will be run by international education providers from Europe and the United States, and the goal is to provide world class vocational training throughout the KSA.

The Technical Trainers College is playing an important role in the Colleges of Excellence, and it is responsible for the education of young Saudis to become teachers at the third level colleges of excellence and in the vocational colleges throughout the Kingdom. The new colleges of excellence are expected to raise academic standards, and the quality of the intake into the TTC is likely to improve.

Currently, the intake of students to the TTC has weak foundations in Mathematics, and the TTC has introduced a preparatory semester to improve the capability of students in basic mathematics. This approach has been very successful, and it has helped to raise standards and confidence among the students.

The KSA has come a long way over the last thirty to forty years. It is important to remember that a generation or so ago, most Saudis were living a semi-nomadic life as Bedouin tribes in the desert. They now recognise the importance of education and recognise that the KSA needs to change in order to provide employment for its citizens. They have made ambitious plans for education reform in the country, and are now implementing these plans. 


\section{Acknowledgements}

I would like to thank my colleague, Dr. Jaime Hernandes Mijangos, for reading an earlier draft of this paper, and for providing many helpful comments and suggestions. I am, of course, responsible for all remaining errors and omissions.

I must also acknowledge the support of Mr. Bernd Schulz during the preparation of this paper.

\section{References}

O’Regan, G. (2013). Mathematics in Computing. Springer (London).

Al-Khotani, S , (2014) “Ten Colleges of Excellence”, Saudi Gazette. June 14th 2013. http:/ / www.saudigazette.com.sa/index.cfm?method=home.regcon\&contentid=20130614169787.

Al-Kinai, M , (2013) Saudi Education Catching up with the World's Best. Nov. $4^{\text {th }} 2013$. http://www.arabnews.com/news/472241

NOSS, (2014) The National Occupation Skills Standards. http://www.ncepa.gov.sa/About.aspx. Retrieved March 2014.

SSS, (2014) The Saudi Skills Standards. Institutional Reviews. http://www.ncepa.gov.sa/INSTITUTIONS.aspx. Retrieved March 2014

IMF, 2013 IMF Country Report No 13/230. July 2013. http:// www.imf.org/external/pubs/ft/scr/2013/cr13230.pdf Murphy, C, (2011) Saudi Arabia's Youth and the Kingdom's Future. Woodrow Wilson International Center for Scholars. Middle East Program. Occasional Paper Series. http://www.youthpolicy.org/library/wpcontent/uploads/library/2011_Saudi_Arabias_Youth_and_the_Kingdoms_Future_Eng.pdf

EdKSA, (2014) Education in Saudi Arabia. Wikipedia Article. http://en.wikipedia.org/wiki/Education_in_Saudi_Arabia. Retrieved March 2014 